\title{
REVISITING THE CONCEPTS OF MONEY, PROFIT AND INTEREST FROM THE PERSPECTIVE OF VALUE AND DIMINISHING MARGINAL UTILITY
}

\author{
Ahamed Kameel Mydin Meera' \\ Hamida Mubasheera
}

\begin{abstract}
This article is a theoretical article that attempts to clarify the inherent meanings of the concepts of profit and interest, i.e. two important concepts in finance, particularly Islamic Finance. These are age-old concepts in economics that still draw confusion among people. Profit comes from trade and interest comes from lending and borrowing activities. While the former is much encouraged in Islam, the latter is strongly forbidden. Nonetheless, in today's monetary and financial circumstances, the market interest rate is being used as a benchmark for the Islamic profit rate, drawing criticisms from many quarters that both are indeed one and the same. Using the fundamental economic concept of marginal utility, this paper attempts to clarify the fundamental difference in these two concepts and their implications for modern finance, particularly Islamic finance. Indirectly in the process, the paper also clarifies the concepts of money and riba.
\end{abstract}

Keywords: Money, marginal utility, monetary system

JEL Classification: D11, E40, E50, E60

1 Ahamed Kameel Mydin Meera is Professor of Finance, Kulliyyah of Economics and Management Sciences, International Islamic University Malaysia (Corresponding author); Hamida Mubasheera is postgraduate student, Kulliyyah of Economics and Management Sciences, International Islamic University Malaysia. 


\section{INTRODUCTION}

Exchange, trade, money, profit etc. are some concepts that have always been integral parts of every human civilization and have played pivotal role in their development. Hence we have become so accustomed with these terminologies that we seldom ponder over the definition and true nature of these phenomena. The consequence of this unawareness can be very detrimental because it is possible that some of these basic processes are malfunctioning in a flawed monetary and economic structure, thereby making life of people much difficult, yet we are having no clue of that as most people lack the consciousness of the correct mechanism of these processes.

A prominent characteristic of Islamic economic system is its absolute prohibition of riba in all its possible forms. Accordingly, the introduction and the rapid growth of Islamic banking and financial institutions have given birth to a renewed interest in the definition of profit and riba. But it seems even after several decades of the launching of Islamic banking, the difference between these two concepts is perplexing to many, academicians and the mass people alike. Hence this paper attempts to revisit those fundamental concepts by removing the complexities. The objectives of the paper are :

- To better comprehend the concepts of money, profit and interest, by incorporating a novel yet easy perception - the concept of value and diminishing marginal utility,

- To highlight the dynamics and superiority of Islamic finance and Islamic economics in clearer terms by expounding on this view point.

The next section, Section 2, introduces and briefly discusses the concept of value. Thereafter the concept of profit is revisited in Section 3 by incorporating the concept of value and diminishing marginal utility. Section 4 presents the nature of profit and interest in a barter economy. Then Section 5 confers the concept of money, an important concept to be understood from Islamic perspective, again by incorporating the concept of value. Profit and interest in a monetary system is discussed in Section 6. Section 7 narrates the implications of the foregoing discussion for Islamic banking and finance. Finally Section 8 concludes the paper. 


\section{THE CONCEPT OF VALUE}

What is value? Why do we value some things and do not value others? The concept of value has been extensively discussed in the classical literature, but here we prefer to remove all complex discussions and keep the concept simple by going to the fundamentals.

We give value to a thing when our senses are stimulated by that thing. We are created with the following five senses.

1. Touch. We get a lot of pleasure from the touch sense. For example when we sit on a soft sofa or sleep on a comfortable mattress. Hence we value soft sofa and a comfortable mattress, compared to a hard bench or a wooden bed.

The sense of touch also includes the inner feelings that emanate from our hearts etc. When we care for orphans or volunteer to help victims of disasters it gives a kind of pleasure and hence our value for such righteous acts. Similar is the case when we care for our young and the elderly.

2. Sight. The sense of sight is very precious. With it we are able to see our surroundings and take pleasure in beautiful sceneries, artworks etc. It also enables us to move around with ease without knocking into things. With sight we appreciate colour and give value to artworks, beautiful women etc.

3. Taste. With the sense of taste we are able to enjoy all kinds of food and drinks. Accordingly we give value to food and drinks that give us pleasure.

4. Hearing. With hearing we are able to listen to the speech of others and make sense of them. Through hearing we give value to good poem or Qur'anic recitation, good music, song etc.

5. Smell. The fifth sense is the sense of smell. Through this sense we are able to enjoy more the food and drinks that we consume. Through the sense of smell we give value to perfumes etc.

Hence it is through our senses that we give value to things. A blind person may not value a beautiful piece of artwork and a deaf person my not value a good piece of music. 


\subsection{Value and Utility}

From the above discussion, it is clear that value is basically attached to utility ${ }^{2}$ derived from things. The more the utility derived, the more value we assign to the thing.

Value is nonetheless quite subjective - different people give different value to things, at different quantities, at different times. For example, Muslims do not give value to pork because they do not derive utility from it. However, non-Muslims might value pork if they get pleasure from consuming it. Similarly people get different pleasure from different food. There are people who love curry while there are others who despise curry.

Value also depends on time and situation. In desperate times, we might even give extremely high value to things. For example, someone who is extremely thirsty, stranded in a desert for some time, might value water very highly. Thus we can say that utility derived from something also differs from person to person and is dependent upon the phenomena of time, place, situation etc.

\subsection{Derived Value}

Sometimes we value things not because we derive utility from them but rather because we have knowledge that others value them i.e. a derived value. We give this derived-value to things because we know we can exchange them with others for other things that we like. For example, there are people who do not smoke but they plant tobacco. Similarly a blind person might value highly a Van Gogh because he knows he can sell it later to others. Also traders are willing to sell their merchandise for paper currencies, that have no intrinsic value in them, simply because they know they can later exchange them for other things from which they can derive utility.

\subsection{Diminishing Marginal Utility: The starting point of exchange}

With knowledge and skills, mankind is able to produce miscellaneous goods and services, including capital goods that can help them to produce more goods and services. The diverse

2 Utility is an economic term referring to the total satisfaction received from consuming a good or service. 
knowledge and skills needed to produce such goods and services are spread widely among people. A person may be able to master only limited knowledge and skills. Hence people normally tend to specialize in what they do best. A farmer possesses the knowledge to produce rice for example, a fisherman the skills to catch fish etc. With specialization, they are normally able to produce more than what they can consume or need for themselves. The extra produce they have can be exchanged for other goods and services; and thereby enjoy what they are not able to produce themselves.

We derive utility from things we produce ourselves, however there is a limit to what we can consume at any point in time. Our consumption of later and later units of our own produce tend to give us less and less marginal utility. 'Marginal utility' is the additional satisfaction or utility that one derives from consuming an additional unit of a commodity or service. This 'marginal utility' is well-known in economics to follow a diminishing pattern. Hence a person might derive low utilities from much later units and hence may want to exchange them for other things that can give them higher utilities.

When one decides on consuming something, one takes it on the basis of this 'marginal utility'. The things which has very low marginal utility to the person, may have high marginal utility to another person. This difference in assigning 'value' or 'utility' gives birth to the most fundamental activity of human civilization- Exchange or Trade.

To illustrate this, let's start with man's consumption of rice. Figure 1 below illustrates the utility derived by a farmer by consuming successive bowls of rice.

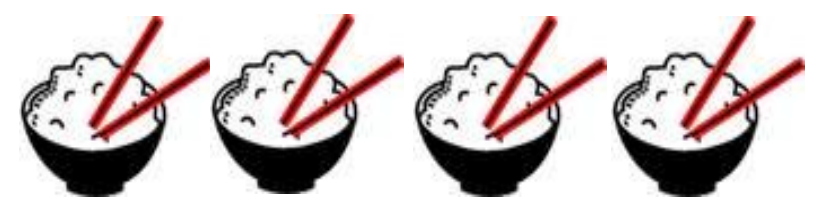

Utils $^{3}$ :

100

50

10 $-20$

Figure 1.

Utility Derived by Consuming Rice

3 It is an imaginary measure of utility which economists normally use. 
The farmer gets high utility by consuming his first bowl of rice, i.e. 100 utils. The next bowl gives him only 50 utils and the next only 10. By this time he is already full. Further consumption does not give him utility at all. Indeed the fourth bowl gives him disutility of -20 , perhaps through a stomachache.

Let's assume a fisherman has similar utility by consuming the fish that he catches ${ }^{4}$.

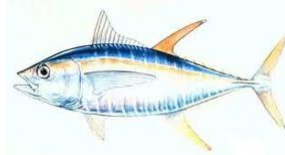

Utils: 100

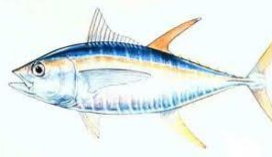

50

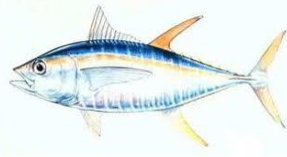

10

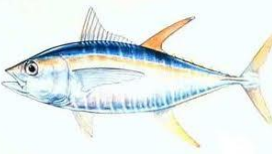

$-20$

Figure 2.

\section{Utility Derived by Consuming Fish}

Now, we note that only a small amount is consumed by the farmer and the fisherman themselves, respectively. What can the farmer, for example, do with the much excess that he has produced? Indeed he has few options with the extra produce, as outlined below:

- Save - for future consumption. But this savings is subject to entropy, the natural order of things where things move towards decay. Rice saved for long periods can get reduced due to rotting caused by weather, eaten by pests etc. To prevent this decaying, the farmer will have to adopt some sort of protection mechanism which may involve costs and efforts like keeping them in a fridge, dry and cool place etc.

- Give - the farmer may derive pleasure by providing rice to his family and parents. He may also give to others like relatives, neighbors, the poor, the sick etc.

- Exchange/Trade - the farmer may exchange some of his rice with others for other goods and services that he may not be able to produce on his own.

- Invest - The farmer can invest further, e.g. replant the rice for the next season or provide his rice as capital for a partnership in farming etc ${ }^{5}$.

4 For simplicity, we assume that the fisherman consume the fish that he catches.

5 When a farmer invests his savings with another farmer on mudarabah basis, they are entering into a partnership, one using his past energy while the other his present energy. If the venture 
Now, we should notice here, that even when one is giving loan to another, the lender is protecting his or her thing from being subject to decay, which is a natural process, as the borrower will repay the thing in similar state after a particluar time. For example if someone kept $5 \mathrm{~kg}$ of rice in his home for one year, it can get spoilt within that time. But if he lends it to another, and the borrower returns $5 \mathrm{~kg}$ of fresh rice after one year, then both the parties are benefitting here, which is contrary to the established notion that only the borrower is the one who benefits in a loan transaction.

\section{REVISITING THE CONCEPT OF PROFIT IN LIGHT OF THE ABOVEMENTIONED CONCEPTS}

As mentioned before, with the extra produce a producer has few options, one of which is opting for exchange and trade. The concept of profit is associated with this option. If a person exchanges the extra produe with other goods and services, which is of greater marginal utility to him than the things he possesses, his utility increases. The same goes with the other person who is engaged in the exchange. Thus in an exchange transaction, both the parties are better off. Let's say both the farmer and fisherman exchange their 3rd unit of rice and fish respectively. Both would give up 10 utils but then gain 100 utils, i.e. a net gain of 90 utils each. This net increase in total utility for both the farmer and fisherman is what profit is all about.

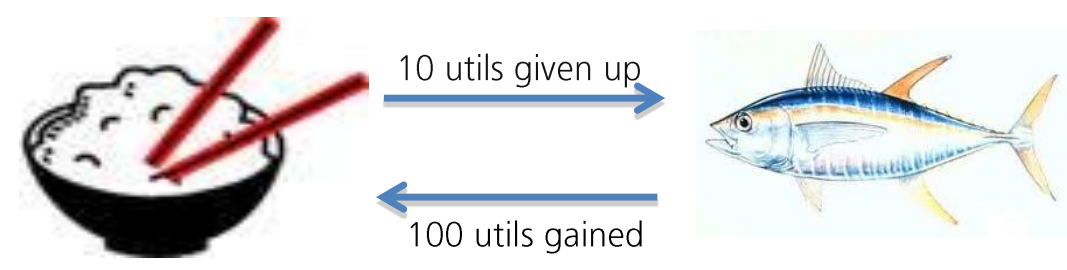

Figure 3.

Rice Farmer's Utility is Increased (Similarlay the fisherman's utility has also increased)

is successful the harvest will be shared among the two. In case of bad harvest or loss, it is erroneous to say that only the capital provider loses because indeed both lose - one his past energy ( in the form of rice seeds) whiles the other his present energy, i.e. efforts put in. 
Hence profit comes from the following: 1) Diverse knowledge and skills that produce diverse goods and services 2) Exchange ${ }^{6}$.

This new look at the concept of profit draws our attention to some of the prominent features of profit:

a) Both the parties involved in the exchange process are gaining through utility increases. Profit, therefore, is not a zero sum game.

b) Profit is generated through creation of value, with the same amount of total goods and services available in an economy. Hence it is possible for all parties to generate profit even when there is no increase in the total amount of goods and services.

The following verse emphasizes ours argument where Allah instructs to do trade with an attitude of mutuality and reciprocity.

O ye who believe! Eat not up your property among yourselves in vanities: But let there be amongst you traffic and trade by mutual good-will: Nor kill (or destroy) yourselves, for verily Allah hath been to you Most Merciful!

(Qur'an, 4:29)

\section{Difference between Price and Value}

Now whether an exchange will take place or not depends on the market situation. In the above example say there is another fisherman who is willing to exchange two fish for one bowl of rice. Then the farmer is likely to be prompted to exchange his rice for two fish instead of only one with the first fisherman. In this way, with many farmers and fishermen in the society, the demand and supply for rice and fish are established in the economy. Thus with the demand and supply of things, a 'standard price' that is the market clearing price, or exchange rate, will be set for every good and service in the economy. This is shown in Figure 4:

6 Say in a remote island, all inhabitants are fishermen who catch the same kind of fish. In such society exchange is not likely to take place and hence profits and standard of livings would be much curtailed. 
Rice

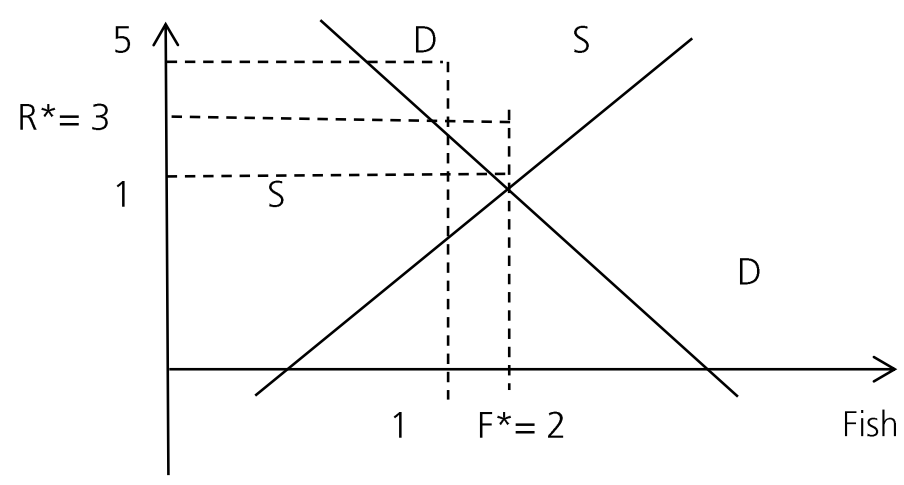

Figure 4.

\section{Demand and Supply Curves and the Establishment of Equilibrium Price}

The $R^{*}$ and the $F^{*}$ are the market-determined equilibrium exchange rate between rice and fish. It is the market clearing price.

In a two person economy, the increase in utility enjoyed by both is indeed total profit. The utility derived determines what value is given to an item. The price paid in monetary units is a reflection of the utility gained. Nonetheless, in a multiple persons economy the price paid may not be exactly same of the true value assigned by an individual to that particular thing or the marginal utility derived. The presence of multiple buyers and sellers establishes the equilibrium market clearing price through the forces of demand and supply, i.e. competition. At the equilibrium price some buyers and some sellers gain. Some buyers gain because they enjoy more utility than the price they paid. Some sellers gain because they get better market price than the prices for which they were willing to sell. This difference between utility and price is termed as consumer surplus and producer surplus, respectively in conventional economics. This is depicted in the diagram below: 


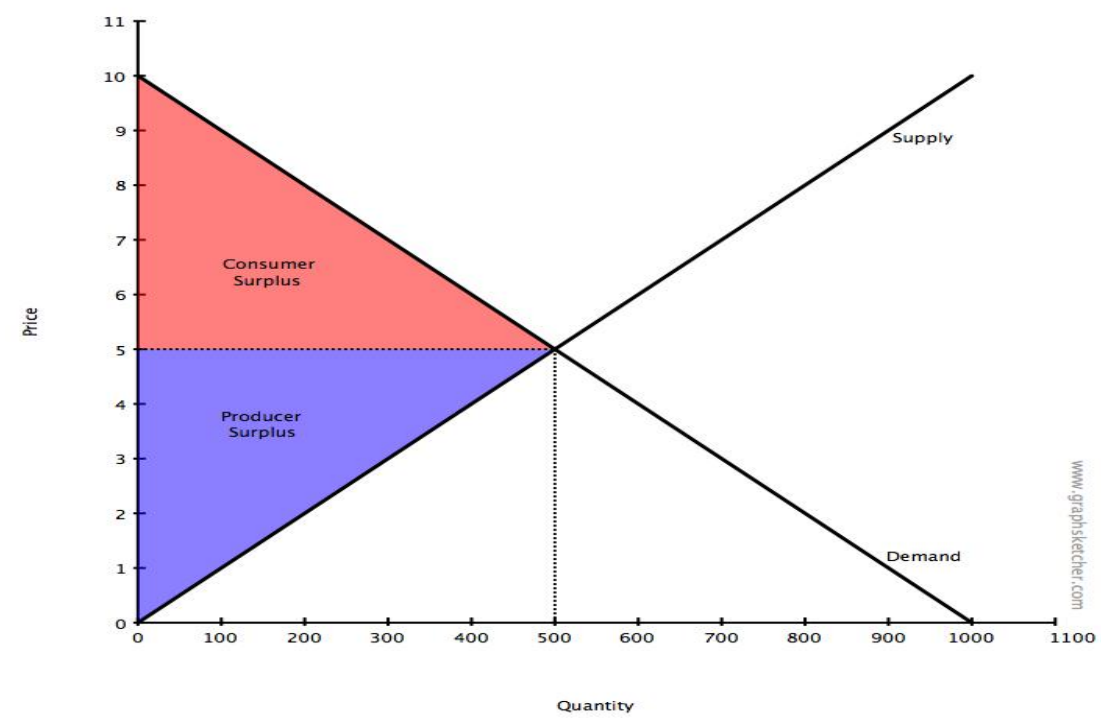

Figure 5.

Consumer Surplus and Producer Surplus

In an economy with many buyers and many sellers, the market clearing price is the termed as the equilibrium price. It is at the intersection between the supply and demand curves. In the above diagram the equilibrium market price is $\$ 5$ while 500 quantity of the item is bought and sold at that price, i.e. the equilibrium quantity.

Here the difference between both the surpluses and profit should also be noted. For example, Consumer Surplus not necessarily equals to the amount of profit. Even when consumer surplus is zero, there can be profit as net utility has been increased through the process of exchange.

However any manipulation of the exchange may contain zulm or injustice. For example, in classical trade, intercepting caravans before they reach the market place and paying below-market price for goods ${ }^{7}$ constitutes injustice. Or taking advantage of situations like in

7 Such activity prevents the caravan from discovering the market price. In Islamic tradition, the prophet (pbuh) had prohibited such intervention. 
our earlier cartoon example where the lemonade seller increases the price of a can of lemonade to one bag of gold. This is like a monopolistic exploitation, where the net total utility may be increased, yet the price paid, i.e. the amount of counter value, was not determined by the market.

\section{NATURE OF PROFIT AND INTEREST IN A BARTER ECONOMY}

After concepts of value, price and utility are illustrated, from the foregoing discussion it is clear that 'profit' is actually the net increase in total utility. So profit is realized only after an exchange is done, it is not recognized immediately after the production of goods or services. For example, a factory that produces computers for example does not recognize profit immediately after the production of computers but rather it recognizes profit only after selling it.

Then what is interest? Interest is any unlawful addition in this process of exchange for which countervalue has not been given or utility has not been received. For example, in our previous instance, if a person lends $5 \mathrm{~kg}$ rice and demands $6 \mathrm{~kg}$ after a year, then this additional $1 \mathrm{~kg}$ is interest as for this the borrower has not received any utility. As we said before, the lender getting $5 \mathrm{~kg}$ fresh rice after one year is enough countervalue for him, for otherwise his savings would be subject to entropy.

\section{UNDERSTANDING MONEY FROM ISLAMIC PERSPECTIVE BY INCORPORATING THE CONCEPTS OF VALUE AND MARGINAL UTILITY}

We have seen that exchange, a most fundamental activity of human civilization is initiated when people assign different value to different things. But the number of exchanges that take place in an economy largely depends on the mechanism of exchange process. If the exchange process is conducted in a barter setting, it has some underlying problems. For example:

1. Double coincidence of wants-means first party's forgone goods must be the wants of the second party and the second party's forgone goods must be the wants of the first party. 
2. Divisibility. For example, if one wants to exchange a bag of rice for beef. The owner of a cow may also want a bag of rice, but how to exchange that? One can't cut part of a cow to exchange for a bag of rice.

3. Too time consuming to find counter party.

Due to the above problems inherent in barter system, people looked for solutions to make their economic activities smoother and more efficient. Hence mankind introduced mediums of exchange that are transferred from person to person, each time a transaction takes place. This medium of exchange is called money. While smoothening the exchange process, money also allows market players to specialize in what they do best. This specialization effect of money increases output and brings about more exchanges and hence further increased total utility and standard of living for the people.

If we go back to the barter exchange system and introduce the concept of money into the picture, we note that money is actually a measure of the value for the marginal utility exchanged. When one buys rice for say RM10 and gets 50 utils of utility, the RM10 is actually the measurement of 50 utils, assuming no other person is also selling rice. However if there are many buyers and sellers, and the price is market determined, then there will be consumer and producer surpluses. Hence, as mentioned earlier the price paid in monetary units may not be the same as the utility received from the transaction.

Now, with this RM10, the rice seller can again do further transactions. Thus this introduction of money into the system increases significantly the number of transactions executed and allows scope for specialization.

Hence to solve the problems of barter exchange, we need a medium of exchange. To achieve this objective, we need a reference point against which the value of all other things will be measured. This reference point needs to have the following characteristics to effectively address the problems associated with barter:

1. Acceptable - i.e. people desire it for its own sake, that is it gives utility to people (i.e. having intrinsic value) and hence need not imposed on people through law. It should not, therefore, have 
seigniorage over its actual value. Fiat money, for example, is imposed on people using the legal tender law.

2. Divisible - this is an important characteristic since divisibility is one major problem with barter.

3. Homogenous - this characteristic is pertinent as it assists the divisibility character. It means if the item is cut into smaller units one need not ask which unit one prefers since all are equal.

4. Mobile - can be easily moved about.

5. Durable - i.e. long lasting. So that it can also be saved for future use.

6. Rare - having high value/quantity (or weight) ratio. Hence a small amount having high value.

7. Stable Value - Having not much industrial or seasonal demand. This would give a stable value-relationship with other things.

With the eight characteristics an item can, therefore, be a stable measure of value, i.e. a reference point for all exchanges, i.e. measure a value of goods, services, investments etc. Because it's a reference point, it is not traded as a commodity. It is, therefore, also not an investment item, but it measures investments and their outcomes.

Precious metals like gold and silver fulfill all the above characteristics. Items like wheat, barley, salt and dates as mentioned in one hadith fulfill all but perhaps the last two. So still they can play the role of money for small transactions within given periods. The first six characteristics are pertinent while the last two are additional desired characteristics.

A unit of the reference point is what money effectively is 8 . Historically, various commodities with the above characteristics have been used as money. Such commodities include cowry shells, salt, wheat, barley, gold, silver etc. People accept them on their own accord since these items have their own intrinsic value from which people derive utility.

8 For example $4.25 \mathrm{gm}$ of gold is called as dinar, or $3 \mathrm{gm}$ of silver as dirham and so forth. 
Some points require special attention here. Firstly, although commodities with intrinsic value have been used as money, money itself, however, cannot be treated as a commodity. To elaborate this, it can be said that, money is a commodity or a standardized service that fulfills all the above mentioned characteristics of measure of value and act as a reference point against which the value of all other things are measured, but it cannot be the subject matter of a contract by itself, hence cannot be sold or leased. The overall concept of money is illustrated in Figure 6 below.

The concept of money starts with Problems of Barter Exchange

People needed a medium of exchange to solve the Problems of Barter Exchange

The medium of exchange is normally an item that is exchanged in the economy that has the following characteristics:
1. Intrinsic value
5. Mobile
2. Durable
6. Rare
3. Divisible
7. Accepted by society
4. Homogenous
8. Not much industrial or seasonal demand

Hence the medium of exchange got to be a REAL commodity or service

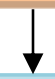

The medium of exchange is now a reference point against which the value of all other things are measured, i.e. a measure of value

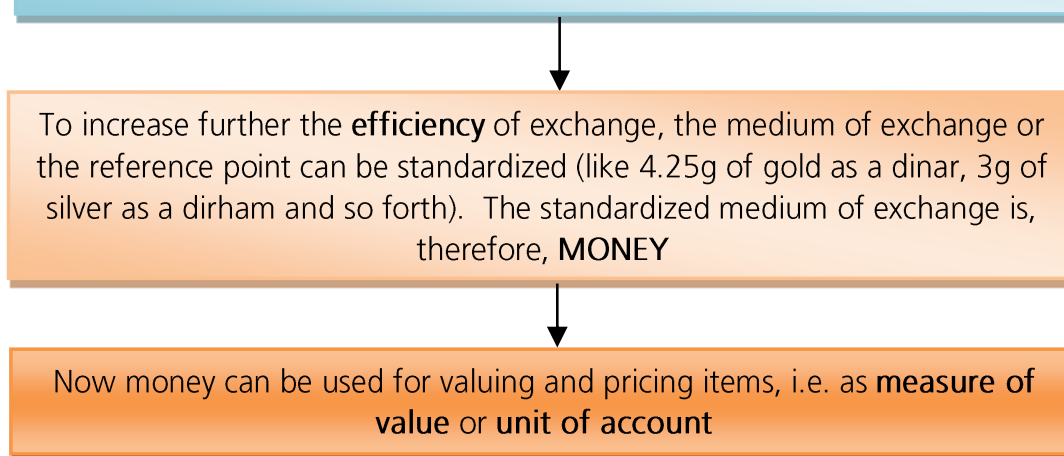

Figure 6.

The Concept of Money Defined 


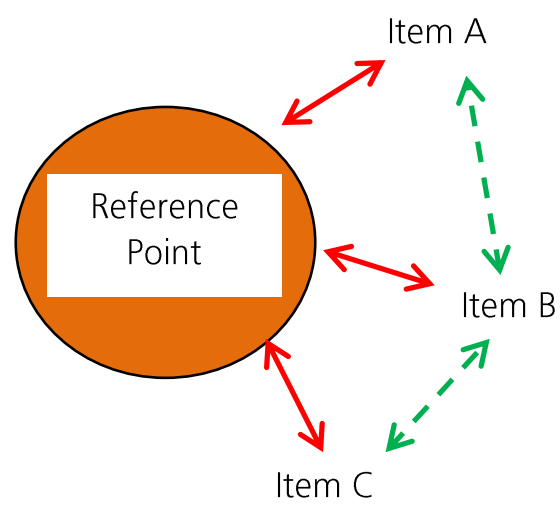

Figure 7.

Money as Medium of Exchange (Commodity) and as Unit of Account or Measure of Value (Information)

$\longleftrightarrow$ When the reference point, like gold dinar, is used for, say, buying item $A$, then it is being used as a medium of exchange. Here money is a COMMODITY and being exchanged for another real thing. It is effectively like a barter exchange and a fair transaction because both of the items exchanged have intrinsic value.

$<--\rightarrow$ When the reference point, like gold dinar, is used for pricing, say item $A$ and item $B$ as being one dinar, then it is being used as a measure of value or unit of account. Hence $A$ and $B$ can be exchanged directly without using gold dinar at all. Here, money is INFORMATION.

The overall concept of commodity money is beautifully expressed in the following hadith (Sahih Muslim):

Abu Said al-Khudri reported Allah's Messenger s.a.w. as saying: Gold is to be paid for by gold, silver by silver, wheat by wheat, barley by barley, dates by dates and salt by salt, like for like, payment being made on the spot. If anyone gives more or asks more he has dealt in riba. The receiver and giver are equally guilty. 
All the above mentioned commodities by the Prophet (s.a.w) have all the six main characteristics of money and all had indeed played the role of money at some point in history.

Now if money does not have an intrinsic value like fiat money, then during the exchange process, there will be no 'just exchange', i.e. injustice would crop-in. This is because, the person who is receiving the commodity is getting a real asset, while the other person, who is getting the money would be deprived of since fiat money does not have any intrinsic value. This injustice is however true only for the first exchange but, nonetheless, this still constitutes injustice, i.e. the seigniorage ${ }^{9}$. The asset ownership structure in the society would also be gradually changed, on a continual basis, by this fiat money system where banks would then become the ultimate owners of tangible resources, basically in exchange for 'nothing', as the cost of mere printing money is effectively zero.

Another pivotal flaw of the current fiat monetary system is that its capacity of money creation out of thin air reduces the monetary value of the real assets in an economy. The amount of utility received from those assets, for a given amount of money, tends to erode gradually as too much money chases too few goods.

This concept of money where primarily it is a 'measure of value' is inbuilt in the very structure of the Islamic economic system. The amount of zakat, hudud punishment, diah, mahr etc. have all been explicitly defined using gold and silver as the monetary reference points. Even now, when the monetary system is fiat in nature, we use gold and silver as a 'measures of value' perhaps without being aware of the fact. For example, we determine the amount of zakat payable on cash by calculating the equivalent monetary worth of a certain amount of gold or silver having in possession, i.e. the nisab.

This primary function of money of being a 'measure of value' requires special attention in the current system, where the main function of money is treated as 'medium of exchange' and also it is propagated that anything, if generally accepted or forced through law to be accepted, is regarded as money. However, such injunctions

9 Seigniorage is the additional value given to money over and above its intrinsic value. For example, say the cost of printing a 100-ringgit note is 20 sen. Then the seigniorage is RM99.80. This is additional freely obtained purchasing power. 
violate the basic concepts of justice and equitable distribution of wealth. Hence the fundamental flaw of the current monetary system is the absence of a just and equitable 'measure of value'.

We should understand that as fiat money does not have any intrinsic value, various authoritative bodies force people to accept it as money via the legal tender law.

However in this era of high technology, it is possible to use a lot of things as symbolic money like paper money, e-money etc. where something convenient being used for day to day transactions, yet it is $100 \%$ redeemable and backed by some commodity with intrinsic value.

\section{NATURE OF PROFIT AND INTEREST IN A MONETARY SYSTEM: ISLAMIC IMPLICATIONS}

A careful study of the above mentioned hadith is enough to illustrate the concept of interest in a monetary system. Scholars have divided the six items mentioned in the hadith into two categories as below (adapted from Nyazee, 2008):

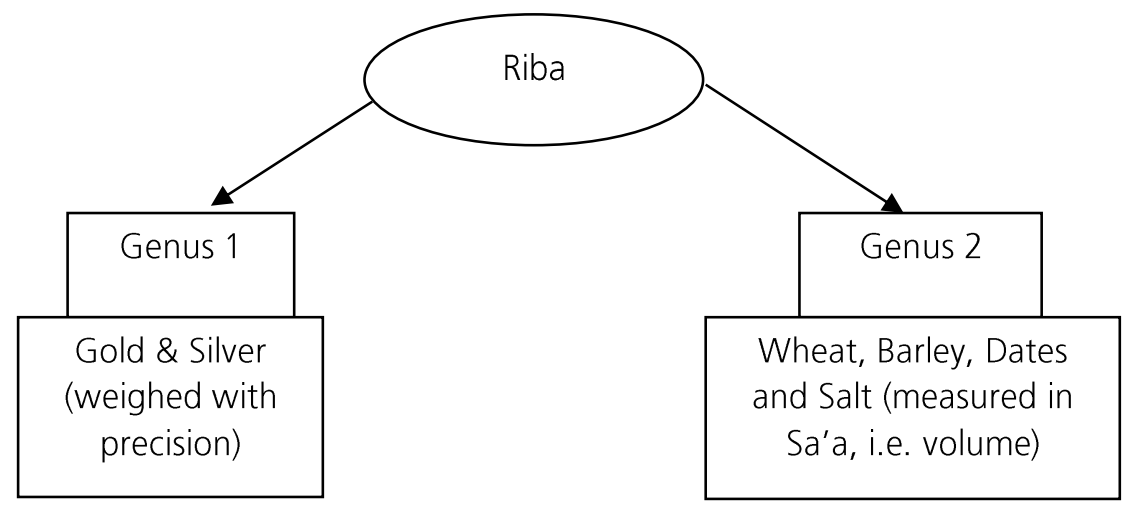

Figure 8.

Acceptable Transactions

- Same Genus, Same Group - Weights must be equal; Spot transaction only

- Same Genus, Different Group - Weights can be different; Spot transaction only 
- Different Genus, Different Group (of course) - Weight can be different; Spot or Delayed

Transactions that avoid riba are, therefore, as shown in Figure 9 below:

\begin{tabular}{|l|l|l|l|l|l|l|}
\cline { 3 - 7 } \multicolumn{1}{c|}{} & Gold & Silver & Wheat & Barley & Dates & Salt \\
\hline Gold & & & & & & \\
\hline Silver & & & & & & \\
\hline Wheat & & & & & & \\
\hline Barley & & & & & & \\
\hline Dates & & & & & & \\
\hline Salt & & & & & & \\
\hline
\end{tabular}

Transaction must be SPOT and SAME WEIGHT /measure

Transaction must be SPOT, but can be of DIFFERENT WEIGHT

or measure

Transaction can be SPOT or DELAYED and can also be of

DIFFERENT WEIGHT or measure

Figure 9.

Transactions That Avoid Riba

By expounding upon the reasons for the above mentioned prohibitions, one can understand the definition of interest, i.e. riba, in a monetary system. When items of the same genus and group are exchanged, they have to be equal in amount and also on the spot. When same genus but different group, then the weight or measure can be different but the transaction has to be on spot. This is, so that no room for injustice remains; both the parties get equal counter value, benefit or utility. Here remains no scope of increase in utility or gaining profit as both the items should be treated as medium of exchange and do not entail the status of a commodity. When the genus is different, then it becomes like normal exchange process, where one is acting as money, while the other playing the role as normal commodity. Hence the transaction can be delayed, as well as different measure or weight can be transferred. From this 
understanding and structure, it is not difficult to see why gold and silver became the dominant money in most civilizations in history ${ }^{10}$.

From the above discussion, it clearly manifests that in a monetary system, when utility is increased during an exchange process, the monetary expression of that increased utility is called profit. So in a monetary economy, there cannot be any monetary profit without the exchange of real goods and services. Ultimately 'profit' always requires involvement and exchange of real goods and services.

In a monetary economy we can also synchronize this traditional definition $^{11}$, i.e. profit is revenue minus cost, with the definition provided in this paper from the marginal utility perspective. Cost price is actually a monetary expression of utility given up, whereas sales price is the monetary expression of the utility gained. The difference entails the amount of profit representing the net increase in total utility. However, in a market economy where prices are determined by market forces of demand and supply, the true total utility obtained is reflected in the market price plus the respective surplus, i.e. the consumer surplus or the producer surplus.

On the other hand, interest in a monetary economy is usually associated with the exploitation of the medium of exchanges, as derived from the abovementioned hadith. When medium of exchange is treated as a commodity itself and profit is attempted from this exchange, then that makes injustice prevalent. Because if the medium of exchange becomes a tradable commodity, then people need to acquire it before being able to engage in a transaction process. It also can be controlled by a group of people who can thereby enslave others, just by owning most of the medium of exchanges.

\subsection{Interest in the Current Monetary System}

Currently, the whole world is indeed using an unprecedented type of money in human history i.e. fiat money that is created out of

10 The present global fiat money system is the result of a political dominance that emerged after World War II. The Bretton Woods system gave the dollar a dominant role relative most other world currencies.

11 The traditional definition of profit (gross) is the difference between sales price and cost price. It just looks at things from the sellers' perspective. 
nothing, mostly via fractional reserve banking, forced acceptance through the legal tender law; and where the power of money creation is limited to some authoritative bodies like banks and government. Moreover, compound interest is charged on the borrower. Additionally, the compound interest formula is an exponential function. Now the fallacy is, that bankers charge interest on money that only they can create out of thin air. How then could borrowers hope to repay loans of this manufactured money plus the interest charges imposed on it?

$$
\begin{array}{ll}
\text { Money Supplied } & =\text { Loan Principal } \\
\text { Money Owed } & =\text { Loan Principal }+ \text { Loan Interest }
\end{array}
$$

For example, say initially, the total amount of state money in existence is $\mathrm{f100}$ million. If bankers now create $\mathrm{f} 400$ mil of bank money there will now be a total money supply of $f 500$ mil. Let us further imagine that the $£ 400$ mil of bank money is loaned for three years at $10 \%$ interest per annum, and that an amount of $£ 532.40$ mil will therefore be due for repayment. Now, if the total money supply at the beginning of the loan period is only $f 500$ mil, where will the extra f32.40 mil come from? There are only 2 possibilities.

1. Not everyone will be able to pay back the loan together with interest.

2. To avoid that from happening, banks will have to supply more money to the economy by creating more loans.

For the first option, we can say that default is designed by the system itself. It is like the musical chair game where the number of players is always one more than the number of chairs which results in the fact that someone has to be out from the game for sure.

Hence, in the total aggregate system, interest can only be repaid in real terms, i.e. banks take away the pledged real goods and services of the defaulting parties ${ }^{12}$. This is how interest merely transfers wealth from the lower percentiles of the society to the top percentile and it is tantamount to theft as it happens without the knowledge and the consent of the affected parties. 
The $2^{\text {nd }}$ option is to create more money. But the fallacy is that when more debts are created, more interest obligations are created too. Hence the debt and interest accrued would only balloon, particularly because the interest portion is an exponential function of the principal.

\subsection{Nature of Interest and Profit: A Comparison}

If we consider the conventional definition of interest, which is 'price of capital', capital has a value that can be invested for further output of goods and services. Risk, liability and effort are incurred to do this. Capital cannot earn interest without iwad or countervalue. Interest is not price of capital, the price of capital is its own value.

Money has been introduced in the economy to facilitate the exchange process by overcoming the difficulties inherent in a barter system. The circulation of money and its distribution has profound relationship with the existence of interest in the economy. A careful look at the economic history reveals that interests were charged when there was a lack of medium of exchange in the economy or when some quarters in the economy are able to control the quantity of money in circulation, where significant quantity of money is in their possession. When enough money is circulated and distributed well in the economy, the economy flourishes with an efficient exchange of goods and services taking place. This of course maximizes value in the economy and hence profits. However when there were shortages of money in circulation, it brought about lowered economic activity, recession, unemployment etc. and the capitalists having most of the money, take advantage of the situation by charging interest ${ }^{13}$. An example of this is the demonetization of silver that took place a number of times in history ${ }^{14}$. While silver and gold were the money during that period, silver was dominant, being used for most small transactions in the economy. Hence the demonetization of silver caused a sudden shrink in the quantity of money, thereby plunging the economy into recession. The capitalists who had gold, which is

13 In recessions, people do have needs to be fulfilled and are willing to work and produce things but nonetheless the lack of money in circulation causes a lot of transactions not to take place; like in a barter economy.

14 For example, silver was demonetized in the United States in 1873. 
now the only money, took advantage of the situation by charging interest on gold borrowings; people had to borrow gold from them so that they could be involved in economic exchanges.

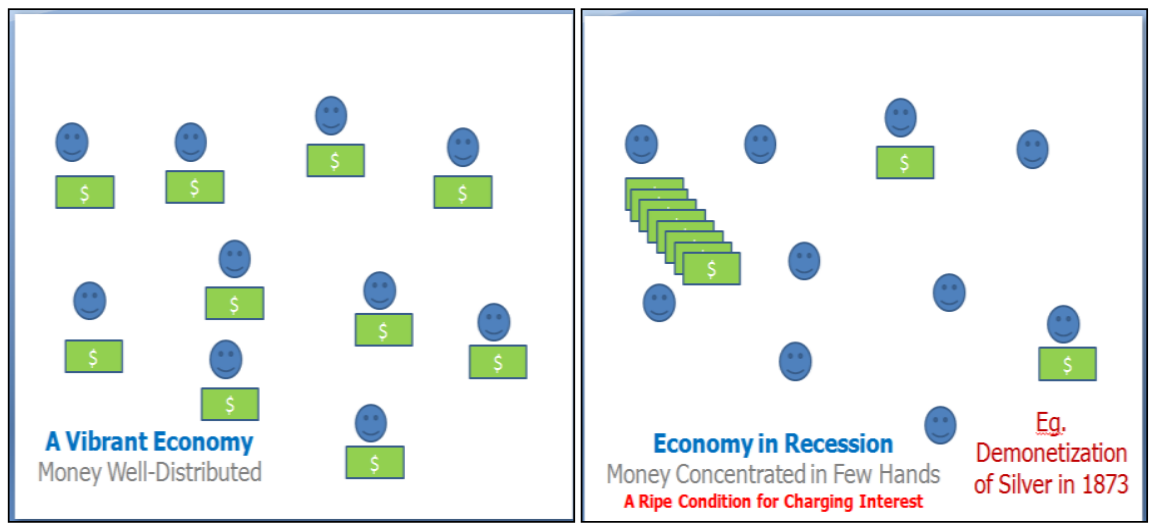

Figure 10.

Relationship between Quantity of Money in Circulation and the Number of Exchanges in the Economy

\subsection{Nature of Fiat Money}

Since the collapse of the Bretton Woods system, markets independently determine the value of national currencies. The collapse had created a new asset class to be played into investment portfolios, i.e. currencies. It has also given birth to an extraordinarily efficient and sophisticated foreign exchange market to link and trade these national currencies. The trading volume in this market reached an impressive $\$ 5.3$ trillion per day (Bank of International Settlements, 2013). But over $95 \%$ of forex trading volume is speculative, and less than $5 \%$ is in fact used for actual international trade of real goods and services (Lietaer, 2010).

Professor John Gray (of Oxford University), in his recent work False Dawn, has remarked: "This virtual financial economy has a terrible potential for disrupting the underlying real economy, as seen in the collapse in 1995 of Barings, Britain's oldest bank." 
The evil results of such unnatural trades were pointed out by AlGhazzali more than 900 years ago in the following words (Ayub, 2007):

"Riba (interest) is prohibited because it prevents people from undertaking real economic activities. This is because when a person having money is allowed to earn more money on the basis of interest, either in spot or in deferred transactions, it becomes easy for him to earn without bothering himself to take pains in real economic activities. This leads to hampering the real interests of humanity, because the interests of humanity cannot be safeguarded without real trade skills, industry and construction."

Another noteworthy difference between profit and interest is that as profit represents creation of value through the exchanging of real goods and services, if the velocity of money is increased, i.e. if money circulation is increased, then profits can be increased too. In other words, more profits can be realized with the same quantity of money. Moreover it is possible for all the balance sheets of an economy to record profits. On the contrary we have shown that interest is a transfer of value, which makes it a zero sum game. It is only possible for one party to gain interest at the expense of other.

The differences between these two concepts can be summarized as in the Table 1: 
Table 1.

The Difference between Profit and Interest

\begin{tabular}{|c|l|l|}
\hline NO & \multicolumn{1}{|c|}{ PROFIT } & \multicolumn{1}{c|}{ INTEREST } \\
\hline 1 & $\begin{array}{l}\text { Source is Knowledge and } \\
\text { Skill and Exchange }\end{array}$ & $\begin{array}{l}\text { Source is control over the quantity } \\
\text { of money in circulation }\end{array}$ \\
\hline 2 & Creation of Value & Unjust Transfer of Value \\
\hline 3 & $\begin{array}{l}\text { Does not necessitate } \\
\text { additional money }\end{array}$ & $\begin{array}{l}\text { Necessitates additional money } \\
\text { since debt is not repayable in } \\
\text { aggregate }\end{array}$ \\
\hline 5 & $\begin{array}{l}\text { Promotes mutual } \\
\text { cooperation among people }\end{array}$ & $\begin{array}{l}\text { Exploitation of people; Promotes } \\
\text { competition among people }\end{array}$ \\
\hline 5 & Positive Sum of Game & $\begin{array}{l}\text { Zero-Sum Game OR even Negative } \\
\text { Sum of Game }\end{array}$ \\
\hline 7 & $\begin{array}{l}\text { Determined Ex-post } \\
\text { economy; usufruct (utility). } \\
\text { Consistent with natural } \\
\text { order of things }\end{array}$ & $\begin{array}{l}\text { Determined Ex-ante } \\
\text { theSystem, inconsistent with the } \\
\text { natural order of things; Goes } \\
\text { against entropy }\end{array}$ \\
\hline 8 & $\begin{array}{l}\text { Does not necessitate to } \\
\text { increase the price of relevant } \\
\text { goods and services }\end{array}$ & $\begin{array}{l}\text { Interest is treated as an expense, } \\
\text { hence it increases the cost of } \\
\text { production and necessitates the } \\
\text { price of relevant goods and services } \\
\text { by being absorbed in the selling } \\
\text { price. }\end{array}$ \\
\hline 11 & $\begin{array}{l}\text { Is determined by real market } \\
\text { forces }\end{array}$ & $\begin{array}{l}\text { Source of good standard of } \\
\text { living } \\
\text { uniform theory of fixing this. }\end{array}$ \\
\hline $\begin{array}{l}\text { Source of a lot of socio-economic- } \\
\text { politico- environmental problems }\end{array}$ \\
\hline Invokes Blessings of God
\end{tabular}




\section{IMPLICATIONS FOR ISLAMIC BANKING AND FINANCE}

The foregoing discussion on profit and interest has far reaching implications for Islamic banking and finance. In Islamic finance, risksharing and economic transactions that end in profit are highly encouraged. But nonetheless, interest-based transactions are termed as being riba and are much abhorred. People have had confusions between trade that brings about profit and lending or credit sales with interest charges, i.e. riba, attached. Many people think both are legitimate economic transactions. But nonetheless, the holy Qur'an explicitly permits trade but forbids riba (Al-Baqarah 2:275).

Those who gorge themselves on usury behave but as he might behave whom Satan has confounded with his touch; for they say, "Buying and selling is but a kind of usury" - while God has made buying and selling lawful and usury unlawful. Hence, whoever becomes aware of his Sustainer's admonition, and thereupon desists [from usury], may keep his past gains, and it will be for God to judge him; but as for those who return to it, they are destined for the fire, therein to abide!

From the above verse, it is clear that even people during the time of the Prophet s.a.w. had the same confusion, between profit and interest. In this article we have attempted to show true nature of profit and interest. These are indeed completely two different things. Nonetheless, in dual banking systems with common monetary environments like fiat money and interest-based, both the Islamic financial system and the conventional system would converge due to arbitrage activities between them. Hence the phenomenon where the interest rate, i.e. the very thing the Islamic system abhors, becomes the benchmark for the Islamic profit rate, thereby causing the Islamic financial system unable to define itself. It is, therefore, hoped that this article would provide some fundamental insight into the nature of these two concepts and help Islamic finance proponents to take the necessary steps to take Islamic finance to the next level where it can truly define itself. 
In today's monetary systems where banks operate under fractional reserve banking system the money it creates is only information. Why pay interest on information then? Why even payback the 'principal'? If the Islamic bank operates under such system, can it legitimately earn profit on mere information?

\section{Targeted Benchmark vs. Demanded Benchmark}

We mentioned earlier that the convergence of Islamic finance towards its conventional counterpart is unavoidable due to arbitrage activities and that accordingly the interest rate is the benchmark for the profit rate. Most scholars do not object to this since it is said that the interest rate is only being used as a benchmark here. Nonetheless, it is important to note here that there is a difference between targeted benchmark and demanded benchmark, that has strong implications. If Islamic finance uses interest rate as a target rate, then that should be perfectly alright but what the convergence theory predicts is that as both the financial systems close gaps between them, the interest rate would become the demanded rate in Islamic finance rather than a targeted rate ${ }^{15}$. In this case the profit rate in the Islamic finance would become effectively a demanded interest rate, thereby making both profit and interest to be one and the same thing.

Another significant feature of the current Islamic financial institutions operating under the fiat monetary system is the widespread adoption of various legal tricks like bai al-inah, tawarruq etc. These are different types of fictitious sales. It is true that to earn a profit, transaction involving real assets (that includes services) is a must, but from our ongoing discussion we have shown that profit is only gained when there is net increase in total utility derived from an exchange of real assets. Both parties must enjoy an increase in utility

15 An analogy for this is as follows. Say a beef producer is inviting people to invest in his business; and say that the investors ask him to match the returns made by the pork producer who is making, say $20 \%$. The beef seller agrees to try his best to earn such return for the investors. In this case the pork return is being used as a targeted benchmark. The actual return would only be discovered at the end of the venture. This benchmarking is perfectly alright. But now let's say the investors demand from the beef producer that he must actually give them $20 \%$ return to match the pork return, without regard to the actual return made from the venture. Now this becomes a demanded benchmark rather than a targeted benchmark, and makes the beef return to be equal to that the pork return. The convergence theory predicts that in Islamic finance, the profit rate would ultimately become equal to a demanded interest rate. 
from the exchange. Looking from this perspective makes the Shari'ah compatibility of the dominant modes of financial products of the current Islamic financial institutions that rely upon legal devices like bai al-inah, tawarruq etc. questionable. Therefore incorporating concept of value into the definition of profit, interest and money as described in this paper deserve some attention to ensure that the current Islamic financial products are truly Shari'ah compliant.

\section{CONCLUSION}

This paper set out to look into the concepts of profit and interest two concepts that are pertinent to Islamic banking and finance from a novel yet easy perspective, by incorporating the concept of value. Through these concepts, the concept of money is also further crystallized. Very often nowadays we hear people criticizing Islamic banks saying that the profit rate charged by Islamic banks is no different from the conventional system's interest rate. Indeed, the interest rate is the benchmark for the Islamic bank's profit rate. Meera (2004) argued that this is because in a dual banking system, arbitrage opportunities occur between the two and prompt market players take advantage of it. Such arbitrage activities would bring about convergence between the two banking sectors, hence why the interest rate is the benchmark for the profit rate.

Nonetheless, this paper attempted to show the very difference between the profit and interest. Profit comes from increased total utility enjoyed, that emanates from knowledge, skills and exchange. Hence, in a fair economy where prices are not manipulated, the more the profit the better it is since it means more utility is being enjoyed, indicating an increase in living standards. Therefore, the notion that traders should not go for high profits or profits should be limited is unfounded. Profit is also not a zero-sum-game i.e. the profit to one is not a loss to another. Indeed, it is possible for all balance sheets in the economy to record profits.

While profit arises from the exchange of goods and services, interest arises from the manipulation or corruption of the medium of exchange. In the past, those who are needy or destitute were charged high interest rates for borrowing money that would allow them to 
transact in the economy. In the present monetary system interest charge exists because the quantity of money in circulation is controlled by someone or some authority, where a scarcity for money always exists. The existence of interest itself causes a scarcity of money because debt cannot be repaid in aggregate since the interest portion of loans does not exist in the form of money.

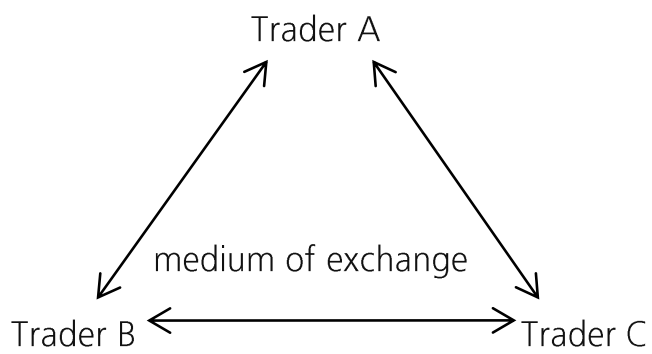

\begin{abstract}
Medium of Exchange facilitates exchange by removing the problems of barter exchange and hence increased PROFIT. But it's the manipulation of the medium of exchange or the corruption of it brings about INTEREST.
\end{abstract}

Figure 11.

Medium of Exchange

Since profit and interest are two very pertinent concepts in Islamic banking and finance, this article suggests that to prevent convergence between Islamic finance and conventional finance and accordingly assist Islamic finance to define itself, it is pertinent that the measure of value in Islamic economics and finance got to be real, i.e. based on some commodity or standardized services. Thus the paper also manifests the forgotten yet most fundamental function of money being a 'measure of value'. The paper argues that this is the primary function of money that has been assigned to it in an Islamic economic system. It also shows how the absence of a just and stable 'measure of value' in the current monetary system is preventing economic and social justice to be established and also inhibits Islamic finance from truly defining itself. Therefore it has been concluded that unless the very structure of the present monetary system is rectified from the core, the Shari'ah compatibility of the Islamic financial institutions operating under the dual banking system will remain questionable and people are likely to continue to be confused between the difference between profit and interest, which are completely different phenomena in reality. 


\section{REFERENCES}

Ayub, M. (2007). Understanding Islamic Finance. John Wiley \& Sons Ltd.

Gesell, S. (1934). The Natural Economic Order. Free-Economy Publishing Co.

Gray, J. (2000). False Dawn: The Delusions of Global Capitalism. The New Press.

Ingham, G. (2004). The Nature of Money, Polity.

Lietaer, B., Ulanowicz, R., Goerner, S., \& McLaren, N. (2010). Is Our Monetary Structure a Systemic Cause for Financial Instability? Evidence and Remedies from Nature. Journal of Futures Studies, Special Issue on the Financial Crisis.

Meera, A.K. (2009). Real Money - Money and Payment Systems from an Islamic Perspective. Kuala Lumpur: International Islamic University Malaysia. (2004). The Theft of Nations - Returning to Gold. Kuala Lumpur: Pelanduk Publications.

Nyazee, Imran Ahsan Khan. (2008). The Concept of Riba and Islamic Banking, Islamabad.

Steiner, P., Purvis, D., Courant, P., \& Lipsey, R. (1990). Economics. Longman Higher Education. 